\title{
The American Way and Its Double in The Crying of Lot 49
}

\author{
Mark Conroy
}

Thomas Pynchon's The Crying of Lot 49 presents itself as in many ways a detective story, a fact not lost on its critics. Tony Tanner, for example, singles out the Southern California variety, especially those by Ross Macdonald. ${ }^{1}$ In a standard Macdonald plot a crime in the very recent past is shown to have been engendered by conflicts a generation old: the past has been, in many if not most of Macdonald's books, a prologue. Similarly, Oedipa Maas, Pynchon's protagonist, searches for the solution to a crime and discovers that it leads not only to herself (one register of her filiation to Sophocles's Oedipus) but also backward to the past generations that have spawned both her and the culprits (another register of that filiation). Lot 49 also presents itself as an anatomy of postwar American consumer society and the legacy it inherits. ${ }^{2}$ It has been frequently noted (by more than one critic and by more than one cheated and sullen undergraduate reader) how the novel fails to deliver on the promise implied by the detective story format. ${ }^{3}$ However, it is partly through its very failure in this respect that it delivers on the second aspect of its agenda: that of describing the land inherited by Oedipa and her kind. To show how such failure aids such success is my purpose here. To do this requires a detour from the narrative--brief but important--the better to return to the world from which Oedipa sets forth on her quest. This world, never far from the foreground of Oedipa's journey, is of course itself a bellwether of postwar American middle-class culture as a whole: that of the media-soaked Mecca of consumerism that is California.

\section{Cultural Meaning: Closure, Control and Maxwell's Demon}

Oedipa's world as she starts out is the "administered world," in a succinct Frankfurt School phrase. ${ }^{4}$ This is a realm of administered goods and services circulated and guided for the many by those few with the resources so to arrange it. It is a commercial system--a "'cash nexus,'" 5 as Oedipa remarks--but because free choice is a necessary part of it, the goods must be coded in such a way as to make them desirable. As a result, one buys as much the signs of the goods as the goods themselves. Jean Baudrillard makes this point when he remarks 
that even in primitive cultures "objects never exhaust themselves in the function they serve," but rather in their "excess of presence . . take on their signification of prestige," hence not only serving the needs of the possessor but also designating his or her "being and social rank." This assigning of prestige to objects has always been a social process of encoding, which Baudrillard calls the symbolic process. What has happened with the advent and perfection of consumer society is that what was once a manifestation of "the transparency of social relations" (as for instance the gift in primitive gift exchange) has become, as a commodity in the administered world, a "sign [that] no longer gathers its meaning in the concrete relation between two people." In lieu of a direct acknowledgement of the way objects are caught up in the social relation, this fact is rendered indirectly, through the commodity-sign's "differential relation to other signs." ${ }^{6}$

The goods on offer, and the media that promote these goods--and promotion is their chief function--become instruments for the normalization of consumer patterns by providing a prefabricated fantasy that any consumer can fulfill through purchase. Fashion and its vagaries provide the most obvious case of the way the administered commodity system can take up styles and, by implication, the selfimages those styles project, and present them as if for the consumer's taking. ${ }^{7}$ The various media of radio, film and TV, not to mention such things as automobiles and tract houses (treated in Pynchon, as in Marshall McLuhan, as forms of sign-making, communication), are presented in all their profusion in this novel as both commodities and vendors of fixed meanings. ${ }^{8}$ For this process to be properly controlled, a closed system must be approximated (though as we shall see, "approximated" is indeed the operative word). The closed system will always tend towards stasis, which is one of the points about the Second Law of Thermodynamics so dear to early Pynchon; and this danger is always present when the circulation of meanings and goods is controlled too tightly. Consequently, the masters of the closed system must themselves constantly be on guard to keep the exchange process going.

The starkest model for this activity is that of Maxwell's Demon, whose sorting and circulating functions slow and reverse entropy within a closed system. The Demon is the figure who "'[k]eep[s] it bouncing'" (178), as Oedipa's ex-lover Pierce Inverarity said was crucial. To normalize the responses of the buying public in Pynchon's world, three things have had to be accomplished: the atomization of consumers into individual units of consumption; the elaboration of a means of making all the goods circulating within the closed system roughly commensurable; and the normalization of tastes and habits. 
The problem for managers of the consumer culture is that all these accomplishments tend in the long run toward stasis and away from active exchange. Like the closed system treated in the Second Law, that of administered goods and their meanings can get suffocating for all concerned if the closure is total.

Consequently, constant effort must be made to inject the system with novel forms of social prestige and interest. One of the points about Maxwell's Demon is that it seems to involve an inverse relation between energy and information. The Demon's canny manipulation of meaning compensates for the loss of differential energy:

[T]here were two distinct kinds of this entropy. One having to do with heat-engines, the other to do with communication. The equation for one, back in the ' 30 's, had looked very like the equation for the other. It was a coincidence. The two fields were entirely unconnected, except at one point: Maxwell's Demon. As the Demon sat and sorted his molecules into hot and cold, the system was said to lose entropy. But somehow the loss was offset by the information the Demon gained about what molecules were where. (105)

As applied to the commercial world commanded by people like the dead man whose estate Oedipa is in turn to administer, Maxwell's Demon is needed to use his intelligence and information (both passively, in soaking up data about the consuming public, and actively, in communicating with that public) in order to keep the exchange of money and goods bouncing: "'that's all the secret'" (178), as Pierce said. Therefore, the managers constantly depend upon meaningcreation, which, while it lies outside the immediate realm of the culture industry, is still seized by that industry for its stock of codes and values. In Pynchon's novel, the values/codes manipulated and circulated with the goods and services of the American consumer culture are not just made up. ${ }^{9}$ Rather, they are taken from an already existing first-order process of symbolization--a process in which "meaning" is chiefly a gerund rather than a noun--a process that occurs in society at large with or without the interventions of consumer culture. This process of symbolization is open to hazard and the miraculous confrontations of one meaning with another: an open process of commonly shared labor. The close of this essay treats one such confrontation in detail. But more generally, any such open process provides the administered world's closed system with its stock of meanings--treated in this instance as a noun not a gerund; and from these stabilized meanings the chief point of "creativity" lies in recombining those codes and attaching them to commodities. ${ }^{10}$

This process of recombination is itself a constant labor: a hidden but all-pervasive labor of advertisement, commerce and shaping of mass taste. The most deleterious effect of this labor is not its 
uprooting of the commodity from its function; as Baudrillard has suggested, the ancient gift and the equally ancient object of barter were always more and other than their narrowly defined use. It is rather in seizing upon the social labor of concrete symbolic value and channelling that labor into its own more abstract circulation of fixed meanings that the commercial system does its harm. This appropriation of symbolic meaning becomes so pervasive that at times, as Lot 49's $\mathrm{Mr}$ Thoth remarks of a Porky Pig cartoon, it "'comes into your dreams, you know'" (91).

Unlike the folkloric symbolization on which it piggybacks, though, this second-order process works to hide the labor that is put into its production. A luster of value is retained from the first-order social symbolization from which the second-order system draws its resonances, but the administered world of commodity-signs uses those subcultural meanings as if they were themselves products, the better to attach them to other products and so preclude the consumer from altering those meanings. The second-order process of meaning-making engaged in by the Maxwell's Demons of consumer society is as much a social labor as is the first-order process upon which the Demons must draw. The difference is that, whereas the first-order process is explicitly social, open to chance and change, and productive of mutually created meanings that are in turn subject to alteration, in the second-order commodity-sign process, the meanings are presented as if completed before the fact, simply there, like the objects to which they attach, for the taking (or the leaving). The social process of meaning-making is occulted on the second-order level: the consumer sees only as much of it as the producers judge will incline the consumer to buy. The consumer's role is not to respond to these symbolizings with his or her own, as in folk culture, but rather to subject him- or herself to the fantasy world prescribed in and by the goods for sale. The hope, in effect, is that the goods and services will provide a flattering mirror into which the individual will then be moved to gaze.

In extremis, the consumer may even attempt to live what is presented as a life on the various media. Pierce's lawyer, Metzger, and Metzger's friend, Manny Di Presso, are aware of the lure of prepackaged values and shamelessly thrive upon it. After Oedipa chides him for his part in the "cash nexus," Metzger argues that his partnership with Di Presso is part of a media nexus as well:

"But our beauty lies . . . in this extended capacity for convolution. A lawyer in a courtroom, in front of any jury, becomes an actor, right? Raymond Burr is an actor, impersonating a lawyer, who in front of a jury becomes an actor. Me, I'm a former actor who became a lawyer. They've done the pilot film of a TV series, in fact, based loosely 
on my career, starring my friend Manny Di Presso, a one-time lawyer who quit his firm to become an actor. Who in this pilot plays me, an actor become a lawyer reverting periodically to being an actor. The film is in an air-conditioned vault at one of the Hollywood studios, light can't fatigue it, it can be repeated endlessiy." (33)

This hall of mirrors replicates itself without cease, and the real lives of these figures seem excuses for the thrill of becoming what they can then see on television or in the movies. But this is not a socially symbolic labor of cultural meaning for either character. It is finally each character's relation to his own ideal image that founds his interest in the other (Manny must play Metzger; Metzger must be played; each wants to be famous). Even those who produce the administered meanings of the media are prey to their parasitic fascination. These meanings rely for their power not on interaction between people so much as on each person's desire to buy for himself his own ideal selfimage.

This ideal self-image is in its essence the functional equivalent of someone else's ideal image, which the consumer then appropriates for his or her own. Pynchon illustrates this process early in the novel through the reflections of Oedipa's husband on his previous job at a used-car dealership, selling that most Californian component of the American dream. For Wendell ("Mucho") Maas, as for McLuhan, the automobile is best understood not only as a vehicle for one's own projection through space and time but also as the vehicle for the projections of administered identity onto the buyer: in short, as part of the apparatus of controlled communication, a kind of medium. As he sees his trade-in customers, "each owner, each shadow, filed in only to exchange a dented, malfunctioning version of himself for another, just as futureless, automotive projection of somebody else's life" (14). Curiously, what "depresses" Mucho about this routine is not the sameness of the cars themselves so much as the human detritus collected and inhering in them. But at least part of the reason the "new" cars cannot renew identity is that they would be the projections of somebody else's life, even if they were new.

The narcissistic hope of self-renewal held out by these trade-ins is always withdrawn; after all, if someone else's dream had not failed, it would not be available in exchange for one's own. The promise of renewal, when tied to the products of the administered market at least, delivers only endless repetition. That this repetition, this mechanical reproduction, is mistaken for renewal is one of the crucial features of the narcissistic self of consumer society. 


\section{Narcissus and Echo: Identity and Iterability}

One of the oft-heard complaints about the character of Oedipa Maas is that the reader gets so few indices of her psychological or social background: no mention of parents, little of education (although we are led to believe that, like the author's, it was consummated at Cornell), very few points of identity at all except for the fact that she is an upscale Californian plugged into mainstream culture and the former mistress of a wealthy speculator.

What we get, to the extent we get anything, is her profile as a consumer: "a buyer of Tupperware, tearer of romaine and garlicker of lasagna, reader of Scientific American," as Molly Hite characterizes her first appearance. ${ }^{11}$ But if the concerns I have noted are central to the text, that profile is more than enough to know about her. She is a happy participant in consumer society and knows little else, but for the occasional feeling of isolation and sadness. Her analyst is retained to cure this, though on the whole her process of plugging in to the media has yielded her a reassuring self-image. Even the fact that her past "fat deckful of days . . . seemed (wouldn't she be first to admit it?) more or less identical" (11) guarantees a certain solid selfhood for her. The narcissistic subject is reassured of his or her identity by two forms of repetition: that in space, through mirror or through duplication by another; and that in time, through the infinite reproducibility of image or sound. The duet engaged in by Metzger and Di Presso demonstrates the mania for both forms of duplication. Yet this promise of an approved "lifestyle" is, while constantly renewed, constantly betrayed by the same token.

The isolation of the subject as the point of sale for the commodity is what insures that the narcissistic appeal will be effective. The consumer desires, on the one hand, the illusion of self-sufficient power, on the other, the approval of others (which the media, as much as possible, would presume to give or withhold). Most of the major figures in the novel--Metzger and Di Presso, as mentioned, but also Mucho, and of course the Californian attempt at a Liverpudlian rock group, the Paranoids--have tried to fulfill the promise offered by the media by themselves becoming active replicators of media sound and image; and in various ways they manifest the dangers of doing this. Oedipa does not succumb as they do; she is at least smarter than that. Further, she is not wholly content with the position that has been assigned to her by the administered world. But to what she attributes her discontent and what she does about it are in their turn also circumscribed by some of the assumptions from which she starts out. 
Oedipa knows that she is the victim of a certain sort of narcissism: this is the sense of her encounter with the Varo triptych. But symptomatic of that very narcissism is the fact that, even as she cries, Oedipa wants to "carry the sadness of the moment with her that way forever, see the world refracted through those tears, those specific tears" (21). To freeze such a moment in life is harder than to preserve a movie in an air-conditioned vault; but the desire to repeat the past and to stop time is the same. (Interestingly, although the triptych portrays girls in a tower embroidering "a kind of tapestry which spilled out the slit windows and into a void, seeking hopelessly to fill the void" [21], and Oedipa applies this to her own isolation, the reverse image--of a consumer in a tower confronted with an already-woven tapestry to fill the void--is closer to her situation at the story's start. After all, the first place Oedipa searches for meaning after learning of Pierce's death and her executorship is "the greenish dead eye of the TV tube" [9].)

Oedipa's isolation is thus at one with her desire for wholeness and self-sufficiency; this in turn is the province of the body which "will become for each individual an ideological sanctuary, the sanctuary of his own alienation" (Baudrillard 97). Oedipa is most foolish to ever have believed that Pierce could be "the knight of deliverance" (22) from the tower she is trapped in, since it is people like him that have built and maintained such towers in the first place. Similarly, while discontented, and with reason, Oedipa cannot so easily remove herself from that tower either, because that tower is also one of pride fortified by and for the consumption of goods and the appropriation of the values and meanings attaching to those goods. As Adorno says, the problem for the subject when he or she would undo these mediainduced bonds of isolation is that the bonds the subject "would have to tear, the bonds of dominion, are as one with the principle of absolute subjectivity" (ND 50). Part of Oedipa's malign fascination with the Tristero itself may spring from its profile as an organization founded on alienation of a sort--the difference being that they are alleged to have alienated themselves from the administered world but not necessarily from other human beings as such, while for Oedipa, to do the one is to do the other.

Just as Oedipa herself is prey to narcissistic yearnings, she is also the victim of others' narcissistic tendencies as they pursue ideal selfimages that are at once complete and accessible. All of the men in her life chase a fantasy of wholeness through the administered images of the media: her husband, who crosses the "bridge inward" (17) with the help of LSD, and who manages to identify himself wholly with the sound of a radio commercial saying "rich, chocolaty, goodness," the 
medium here quite literally become the only possible message ("'Everybody who says the same words is the same person if the spectra are the same'" [142]); Pierce, whose ventures in self-projection began in San Narciso; and, as mentioned, the actor/lawyer Metzger.

When Metzger seduces Oedipa, Narcissus finds for a moment his Echo (the seduction scene is Echo Courts). He reclaims his lost youth then, not only by running his old movie on the local channel (possibly by arrangement with the station), but also by possessing Oedipa. To what extent he uses the movie to beguile Oedipa and to what extent it is for his own amusement is ambiguous.

Insofar as there is a clue to what Oedipa will find when she intuits the "Tristero system," it is in the way "that night's infidelity with Metzger would logically be the starting point for it; logically" (44). The "logic" here would, in direct plot terms, derive from Metzger's being Pierce's lawyer, and from the fact that the TV screen that prompts the seduction presents the war film Cashiered alongside the map of Pierce's artificial lake containing "real human skeletons from Italy" and carrying a "promise of hierophany: printed circuit, gently curving streets, private access to the water, Book of the Dead ..." (31). The fact that a blown circuit interrupts the TV during their climax seems to portend escape from this administered meaning; and indeed, the fact that the film itself is a surprise--Oedipa's bet that it will end badly for the heroes is, shockingly, correct--would appear to suggest that the quest she initiates after this seduction will break out of the official version of history implied by this Hollywood war picture.

But what is more significant about the coupling of Metzger and Oedipa--and by extension about the quest whose "logic" is spawned by that coupling--is what it pretends to be but is not. It is, to start with, not much of a relationship: Metzger mistakes Oedipa's "sharp breath" (31) at seeing the map of Fangoso Lagoons as being for him, one private hierophany getting in the way of another. If she desires "to bring to an end her encapsulation in her tower" (44), then being seduced by Metzger, a fellow mirror-gazer, will hardly do it. If she traces her interest in Tristero back to this affair with Metzger ("it's all part of a plot, an elaborate, seduction, plot. O Metzger" [31]), then just as the affair they conceive promises deliverance from self but delivers only the reality of the self's doubling, so also the Tristero obsession for which that affair is "logically the starting point" promises deliverance from the consumer society's fixed meanings but delivers only an imaginary other system, one mirroring in reverse the dominant system and its values. What fascinates her in Tristero may be the possibility of "a real alternative to the exitlessness, to the absence of surprise to life, that harrows the head of everybody American you 
know" (170); but as with Metzger, what she really finds in her version of Tristero is the double of the world from which she began.

\section{The Demon of Analogy: History as Theater}

Upon Pierce's death, with its miraculous violence (cf. 14), Oedipa is shocked into becoming an active reader of the past and of cultural meanings: in addition to being given a will to read, Oedipa develops a will to read. ${ }^{12}$ What she desires to read in sorting out Pierce's estate, though, is the "Book of the Dead" (31), whose "hierophany" is bound up with the San Narciso housing development. The tract's "hieroglyphic sense of concealed meaning, of an intent to communicate" gives Oedipa the feeling that "on some other frequency ... words were being spoken" (24-25). Oedipa senses that the secular pattern of "lifestyle" and its cash nexus contains the revelation of something in much the same way her husband, a d.j., tries "to believe in his job" but still feels excluded from "the faithful ... knowing that even if he could hear it he couldn't believe in it" (25).

The death of her lover does pierce Oedipa's sense of insulation, of "buffering," she having felt her own life "as if watching a movie, just perceptibly out of focus" (20). The shock of death, along with the attempt at posthumous meaning by which Oedipa hopes to recuperate that loss, provides what motivation there is for her to "execute a will" rather than remain will-less (cf. Quilligan 187). Still, it is at first out of loyalty to Pierce's memory that she does it, searching through his testament for her revelation as his disciple. ${ }^{13}$

Executing a will implies retracing the past, assessing a legacy: a final act of echoing to a dead Narcissus. But rather quickly, this more reverential mode is augmented by the role of detective, retracing the past in a different key. The strange ending of Cashiered, an altogether too raw conclusion for a part of America's mythic past, presages the more skeptical attitude toward the postwar past Oedipa soon adopts: such an unhappy ending suggests the possibility of a less glorious beginning for postwar America as well. More narrowly, this movie and its commercials prepare for the mystery of the dead $\mathrm{Gl}^{\prime} \mathrm{s}$ made into charcoal by a process that seems rather far outside the one portrayed in the official Second World War imagery. Such treatment serves also as warning that some ways of recuperating the loss of death do anything but justice to the memory of those who have died.

It is the desire to find out what the fate of those dead Gl's may mean--not so much a conventional detective's question of who killed them (the assumption is it was starvation and the Germans) but rather the question of the meaning of their death and subsequent fate--which 
makes Oedipa pay attention when one of the Paranoids' girlfriends remarks the similarity between the story of the Gl's fate and "'that ill, ill Jacobean revenge play we went to last week' " (63). Oedipa attends a performance of that play as part of her will to read the Book of the Dead.

In The Courier's Tragedy, the analogue for the dead Gl's is the Lost Guard of Faggio. In an apotheosis of the dead as speakers of the truth of the past, the Lost Guard themselves are used to reveal how they died. Niccold, a rival of Duke Angelo's, is killed carrying a letter from the Duke that testifies (falsely) to Angelo's good intentions; when Niccold's body is recovered, the letter accompanying it has undergone more of a change than Niccolo himself:

It is no longer the lying document Niccolò read us excerpts from [earlier in the play] at all, but now miraculously a long confession by Angelo of all his crimes, closing with the revelation of what really happened to the Lost Guard of Faggio. They were--surprise-every one massacred by Angelo and thrown in the lake. Later on their bones were fished up again and made into charcoal, and the charcoal into ink, which Angelo, having a dark sense of humor, used in all his subsequent communications with Faggio, the present document included. (74)

There is also testimony that the dead Guard themselves have miraculously rewritten the document: " $A$ life's base lie, rewritten into truth [is their description of it]. I That truth it is, we all bear testament, / This Guard of Faggio, Faggio's noble dead" (74). At first, the Duke has turned the dead guard into the raw material for a self-promoting lie; but when the actual historical scene is returned to, the truth of the past is revealed, Angelo's lie is reversed, and the dead revise and edit the living. So if others, in preserving the dead, have turned them to ill uses, then Oedipa can use their remains as clues to the truth about their fate and what their fate portends.

The Tristero model has power for Oedipa because it contains a metaphor for the dead men at the bottom of Fangoso Lagoon. This metaphorical transfer, a form of the circulation of meanings, convinces Oedipa that this is not coincidence but equivalence. ${ }^{14}$ One clue to her breathtaking ability to make historical hypotheses on the basis of fictional evidence may be found in her attitude toward metaphor itself: oddly enough, metaphor is characterized for her not by its ability to force together two disparate semantic force-fields but rather by whether it is true or false. Metaphor to her is "a thrust at truth and a lie, depending where you were: inside, safe, or outside, lost. Oedipa did not know where she was" (129). Oedipa makes what discoveries she does precisely because she does not know where she is. The problem is that Oedipa overlooks the miraculous possibilities within the "act of metaphor"--the miracle Jesús Arrabal defines as "'another 
world's intrusion into this one' " (120)--in favor of trying to decide what truth claims such an act can make. By turning the act of metaphor from a process open to hazard into a puzzle with a predetermined solution, Oedipa turns a matter for wonder into a mere question of belief.

Oedipa pursues the historical possibilities and paths not taken, not for their own sweet sake, but for how they can further the revelation of meaning by returning to the origin of meaning. In like fashion she explores the various subcultures of the West Coast not because she wants to join--indeed, her isolation during her tour of San Francisco is striking--but because they may reveal the truth behind what cannot be assimilated to the official version of history for postwar America, truth which, if absent, would leave these groups as mere "storm-systems of group suffering and need" amid the culture's "prevailing winds of affluence" $(178)$. Oedipa's interest in these groups is prompted by the notion that they may continue a history posited by The Courier's Tragedy. That play, by proffering a word ("Trystero"), gives Oedipa a means to sort all the unassimilable remnants of subcultural defiance and indifference into one box despite their diversity, and so provides the needed double, or Other, or, in director Randolph Driblette's term, "Adversary" for the administered world.

The connection between the play and the truth of history is strengthened by the further transfer of meaning within the play itself, first by Angelo's use of the product of his crime as the vehicle for denying his criminality, and then by the miraculous use of the lying document itself as the vehicle to reveal that criminality. In the same way, Pierce used the dead Gl's--and by extension the sacrifices of others in that war which laid the groundwork for postwar prosperity--to advance his own designs, turning the past to his own use along with its dead; but the completed legacy, written in the ink of that negated past, could itself be used as the vehicle for revivifying that past, "[a]s if the dead really do persist" (99).

Oedipa's readiness in transferring meaning from the play to history ignores the crucial disjunction between the dead of Fangoso Lagoon and the Lost Guard of Faggio. The latter had their bones turned into the ink which was used to deny the history that produced what was being used to write it, and so the literal truth that was part of the very material of the Duke's document took its revenge on the lie it was used to construct. But the easy opposition of truth and lie that works in the play does not work in the case of the dead Gl's. The meaning of their sacrifice has been somehow occulted or distorted, perhaps; but it is not a matter of a revelation to be affirmed or denied, a crime to be proven. It is rather a much more pervasive matter of complicity, and its 
attendant collective amnesia, not a specific crime and coverup, that is at issue.

Symbolic of this difference is the fact that no document comparable to that accompanying Niccolo in the play ever emerges from Fangoso Lagoon. The dead men are neither repositories of truth nor the victims of a lie; nor are they truth or lie themselves. Rather, they are counters in a cultural play of metaphorical substitution in which they take their ever-changing positions as commodities. Their bones have become part of the circulating system of goods and have taken no revenge comparable to that of the dead in the play. The dead of The Courier's Tragedy, having been turned to the purpose of lie, reverse the purpose by revealing the historical truth; the dead Gl's, having been turned to the purpose of commerce, reveal no comparable historical truth themselves.

At this point, though, Oedipa still believes that in sorting her lover's estate she can, while executing his will, reverse whatever "base lies" distort historical truth; this way, the parchment of Pierce's own testament can also become that document in which the dead rewrite deceit into truth. The possibility that Tristero's criminality implicates the will's testator rather than posing a mere external threat occurs to Oedipa quite late. But even when it does, she must persist in seeing words and meanings as governed by their relation to a transcendental signified: a revelation that authorizes a closed system of meaning, or at least patterns a stark struggle of order and reverse order, truth and deception, good and evil.

The only alternative to this pattern of revealed meaning Oedipa can credit is solipsism. This is precisely the threat posed to her by Driblette, the director she meets after the play:

"If I were to dissolve in here," speculated the voice out of the drifting steam, "be washed down the drain into the Pacific, what you saw tonight would vanish too. You, that part of you so concerned, God knows how, with that little world, would also vanish. The only residue in fact would be things Wharfinger [the playwright] didn't lie about. . . But they would be traces, fossils. Dead, mineral, without value or potential." (79-80)

Driblette eventually is washed into the Pacific; but although his fate suggests analogies with Niccolod's, he assigns the opposite significance to the possible result. Whereas revelation emerges from death in the play, Driblette expects that the world revealed by the play would vanish. The textual meaning exists only if it inhabits someone's spirit, confers identity: the other side of the bargain in which he gives the "words and a yarn" some "life" $(80)$ is that they grant form to his life in turn. But it is a form that, as with the mass-culture consumers throughout Lot 49, requires the bearer's isolation to achieve. Hence, 
Driblette walks into the Pacific wearing his costume from The Courier's Tragedy. For him, the historical reality is "residue," only "traces, fossils;" they produce significance only when he, like the projector in the planetarium, activates them, and when he goes, their significance disappears.

The solipsism of this view is the furthest extension of the mediafed narcissism of the rest of the novel. At first, Driblette might seem the reverse of the narcissist, creating a world rather than accepting one by trying to find himself in it. But in fact this appearance of mastery is the reality of submission; and as with Mucho's fantasy of world harmony, it is enacted only in the interior of the self, which is why it will vanish when Driblette becomes a driblet in the vast Pacific. ${ }^{15}$

The analogy between Driblette and Niccold seems apposite, since Niccolo is "the rightful heir and good guy of the play" (65) who "hears the tale of the Lost Guard" (68) and is pursued by a band of evil figures finally named Trystero. Just as Niccold's murder by Trystero reveals Duke Angelo's massacre of the Lost Guard, so Driblette's walk into the Pacific--murdered, in a sense, by his own absorption into a play about Trystero--should yield similarly spectacular results. Seeking such a revelation after Driblette's funeral, Oedipa tries to "reach out, to whatever coded tenacity of protein might improbably have held on six feet below. . . . She waited for the winged brightness to announce its safe arrival. But there was silence" (161-62). In a binary formula of the type that becomes manically typical of Oedipa, she concludes: "Either she could not communicate, or he did not exist" (162). Although Driblette is the director of The Courier's Tragedy, he enters the Pacific wearing the costume of the character he plays, the "colorless administrator, Gennaro" (75), who is left alive and alone at play's end. It is not revelation Oedipa receives, then, but, as Driblette predicted, only "traces, fossils"--and "words" (151).

That this analogy breaks down so completely is itself clue enough to the inappropriateness of the play as the crucial means of suturing a historical narrative together; "Trystero" does not necessarily carry across to "Tristero." But beyond that, the metaphysical armature upon which the original Trystero is presented is equally misleading. Part of Driblette's spoor, seemingly the essential part, is the evidence that the version of the play performed the night Oedipa attends, in which the word "Trystero" is spoken, is indebted to a subversive parody of the play done by the Scurvhamite Puritan sect, whose tenets are as follows:

Their central hangup had to do with predestination. There were two kinds. Nothing for a Scurvhamite ever happened by accident, Creation was a vast, intricate machine. But one part of it, the Scurvhamite part, ran off the will of God, its prime mover. The rest 
ran off some opposite Principle, something blind, soulless; a brute automatism that led to eternal death. (155)

This metaphysic is virtually what Oedipa herself adopts as she explores the question of the supposed "Tristero" conspiracy: the stark opposition between one destiny for the saved and a dire death of the soul for the damned. Indeed, the fate of the Scurvhamites parallels in many respects Oedipa's own:

The idea was to woo converts into the Godly and purposeful sodality of the Scurvhamite. But somehow those few saved Scurvhamites found themselves looking out into the gaudy clockwork of the doomed with a certain sick and fascinated horror, and this was to prove fatal. One by one the glamorous prospect of annihilation coaxed them over, until there was no one left in the sect, not even Robert Scurvham, who, like a ship's master, had been last to go. (155)

This passage anticipates the final pages of the novel, where Oedipa considers joining the Tristero. But the entire metaphysical baggage of Manichean-style division into good and evil principles, with their opposite machineries, bears a strong resemblance to what Oedipa is left with, perhaps because she finds its assumptions congenial. It turns out that the Scurvhamite version of the play is the only one which includes the explicit reference to Trystero, and, further, that there is no rational reason to assume that the Trystero of the play has continued down to the present day: "the libraries told her nothing more about Tristero. For all they knew, it had never survived the struggle for Dutch independence" (162). Yet somehow the analogical power of the play as a medium of revelation makes Oedipa believe in the teeth of evidence to the contrary that it provides the interpretive clue to all of the subcultures she encounters: to the muted posthorn sign, the Peter Pinguid Society, Inamorati Anonymous and the like. ${ }^{16}$ Edward Mendelson has pointed out that "in the middle of the fifth chapter of the book the entranceways, the alienations . . . suddenly disappear: the repetitions [of the post horn and such] stop. For perhaps thirty pages Oedipa receives no immediate signs of the Trystero, nothing more than some historical documents and second-hand reports" (Mendelson 132). In order to pursue the historical data on the Tristero, Oedipa must turn away from the concrete, living data that has always been around her (but that may or may not point to Tristero); and this necessary turningaway is symptomatic.

The Courier's Tragedy, since it is a courier's tragedy, concerns the transfer of communication; but it is itself implicated in this transfer. It is a kind of metaphor, a carrying across, that "turns and taxies across the sea" (cf. 119) from centuries-old Europe to present-day America. Oedipa chooses to see it as revelation rather than as metaphor, as a 
historical origin that explains and determines the present rather than as an analogy that, in part, she herself makes and that, in part, is provided by fragments of evidence. Unlike the dead men in the play's lake (although their "bones were fished up"), the GI's in the historical Lago di Pieta have been moved to another place; such meaning as they had has been transferred and in the process altered, as they have been carried across the sea. The symbolic meaning of the dead is thus already caught up in the circulation of signs, here commercial signs.

One could, of course, construct a model in which the Trystero conspiracy adumbrated by the Scurvhamite-influenced performance continues to the present day. That is what Oedipa does, but there is no compelling reason within the evidence itself to do so, despite some striking analogical similarities. This is why Driblette's walk into the Pacific, a gesture comparable to Niccolo's fate in the play, has the opposite result, yielding not some authorizing revelation of origin and end but simply more "'words, words'" (79).

If this is the case, the question remains: Why, without compelling evidence, does Oedipa feel obliged in the first place to pursue the Tristero conspiracy as if it continued to elaborate the destiny depicted within a Jacobean revenge play? What about Oedipa's own assumptions makes this such a seductive possibility to carry forward? What impels her to literalize the metaphor, to treat this play as governing her interpretation of historical events, and history itself as a form of revelatory theater?

\section{Ones and Zeroes: The American Way and Its Double}

In seeking a reason for Oedipa's embrace of the "Tristero" solution to these historical puzzles, and for the feel of plausibility inhering in that solution despite its objective limitations, we must return for a moment to consider the administered world, whose tower the reader, like Oedipa, may too easily assume to have left. What we sketched in the first section was only a partial description of consumer society in postwar America: the secular aspect, we might say. Underwriting this world is also a kind of civil religion of American destiny, whose arche and telos authorize and guarantee the transactions of the commercial arena; this authorization unfolds the destiny of the unitary state and its favored citizens. Thus do the purely private endeavors of entrepreneurs and buyers participate in an authorized public historical narrative. One thinks in this connection of the dual connotations of the term "American way of life": at once a commercial meaning (home ownership, prosperity, the "dream") and a 
state meaning (those freedoms that must be defended against the other, the Adversary).

The partnership of government and business which the defense contractor Yoyodyne, "San Narciso's big source of employment" (25), exemplifies is a pervasive theme here, going all the way back to the Post Office, set up chiefly as a public means of assisting private commerce. Beyond that, the activity of consumption as such is given the imprimatur of civic duty in the struggle against the USSR. This adversary, perhaps by virtue of the same "ritual reluctance" (71) that forbids the name of Trystero to be spoken during most of The Courier's Tragedy, is scarcely mentioned; but the Scurvhamite pretext, the strategy of exclusion based on election and preterition that is such a frequent Pynchon theme here and elsewhere, draws particular force from the confrontation of light and darkness that has prevailed since the Second World War.

It is against this background that Oedipa's nostalgic reflections on the 'fifties, whose child above all she is, are best understood:

For she had undergone her own educating at a time of nerves, blandness and retreat among not only her fellow students but also most of the visible structure around and ahead of them, this having been a national reflex to certain pathologies in high places only death had had the power to cure. . . . Where were Secretaries James and Foster and Senator Joseph, those dear daft numina who'd mothered over Oedipa's so temperate youth? In another world. (103-04)

The "dear daft numina" in question are quite likely John Foster Dulles, Secretary of State under Eisenhower and chief promoter of the civil religion of anti-communist brinkmanship; James Hagerty, Eisenhower's press secretary; and Joseph McCarthy, notorious anti-communist crusader. A "numen" is a guardian deity, and these figures are said to have "mothered over" Oedipa's youth. Although "daft" conveys a telling condescension to their crusading zeal, "dear" is surely not too implausible for this Young Republican of yesteryear. As one of the few explicit references to formative forces in Oedipa's past, this passage has special import.

Beyond accounting for Oedipa's feeling of isolation as she walks across Berkeley's mid-sixties campus, the passage tells us of the categories of America's civil religion available during Oedipa's time of maturation. The enemy had been clearly defined and marked with a teleology and cultural values the opposite of our own. Its victory would inevitably mean our defeat. It was not merely outside the pale but in active contestation of the American way of life: if it won, lie would extinguish truth. But since the principle upon which this enemy operated was not godly, there was no question of its victory. Oedipa was nurtured on this kind of thinking, with its world of truth and lie, 
good and evil, and national destiny. The possibility that the nation had no unitary destiny to begin with--that this was an abstraction needed by the numina of Cold War civil religion--was not considered. Consequently, when Oedipa sets out to find a box for the nameless oddities she encounters in San Francisco, she takes the Tristero conspiracy as the most convenient organizing principle.

The paradox of Tristero is that it has the effect of taking Oedipa out of the administered cocoon, yet in a fashion that insures she will never fully appreciate or understand what she has discovered on the outside. ${ }^{17}$ During her "dark night of the soul" in San Francisco, Oedipa wanders amidst the human wreckage of consumer society, those unassimilable to its imperatives and its values. Were it not for their imputed connection to the Tristero narrative, their existences would be quite simply waste, meaningless, since for Oedipa, to be the waste of the official society is to be meaningless. The starkest instance of this may be Oedipa's encounter with the children in Golden Gate Park who claim to be dreaming their gathering: "The night was empty of all terror for them, they had inside their circle an imaginary fire, and needed nothing but their own unpenetrated sense of community" (118). When she corrects their jumprope rhyme to make it accord with her research into the Thurn and Taxis mail system, they tell her they have not heard it that way: "Oedipa, to retaliate, stopped believing in them" (119). This episode dramatizes two things about Oedipa's quest: it ignores specific, socially evolving processes of meaning-formation in favor of subjecting these to one all-encompassing narrative (in this case the Tristero counternarrative); and it sets off from the assumption that the reality encountered is a brute given, a revelation of either God or the devil to be credited or dismissed, believed or disbelieved.

What this approach leads to, of course, is expressed at the end of the novel in the familiar passage with the stark binary choices, its ones and zeroes all in a row (181-82). By mounting the Tristero quest, Oedipa has come both to discover an ever larger swath of history and also to be ever more isolated. Her state, finally, is close to that of the paranoid, as she declares to herself:

\footnotetext{
Either you have stumbled indeed... onto a network by which $X$ number of Americans are truly communicating whilst preserving their lies ... for the official government delivery system. ... Or you are hallucinating it. Or a plot has been mounted against you. ... Or you are fantasying some such plot, in which case you are a nut, Oedipa, out of your skull. (170-71)
}

The problem with this formulation, which Oedipa herself realizes later, is that it does not exhaust the possibilities at all. Although she has "heard all about excluded middles" and what "bad shit" (181) they 
are, this does not stop her from excluding a number of other possibilities from her consideration. There is, for example, the obvious possibility that Tristero is a sort of joke, and not necessarily Pierce's either; or a fad; or a genuine network for $X$ number of Americans but not for all Americans who may have withdrawn from the official "life of the Republic" (124). This last detail is critical, because much of Oedipa's interest in the Tristero conspiracy arises from the conviction that the detritus of society can be redeemed only through an overarching narrative: "either . . . a transcendent meaning, or only the earth" (181). The unassimilable marginalia of consumer society, like the dead themselves, are only earth if they cannot be made part of a larger paradigm of transcendent meaning: meaning which here assumes the aspect of a double for the meaning of the official culture as such. ${ }^{18}$

Caught within her self-imposed matrix of ones and zeroes, Oedipa has returned to her tower of Chapter One with a vengeance. The process that has led her thinking to this place can be traced to the quasi-religious justification of the American way associated with those numina of her youth mentioned above. Elsewhere, of course, Pynchon traces theories of National Destiny back to the founding fathers and the Calvinist Puritans. ${ }^{19}$ Here the chief touchstone is a postwar cultural and political reality, insofar as Oedipa is its carrier. Her reduction of "diversity" (181) to binary choices makes sense when the sacred narrative of the American way forms the assumption behind so much of her thinking.

We saw initially how the consumer society takes over the socially active meaning process, detaches the meanings from their social context and presents them to potential consumers as fixed, the resultant social identity as conferred. This "secular" aspect of the American way is complemented by a "sacred" aspect of official national destiny. This grand narrative allows the individual to take his or her place within it, and so also, like the administered world of consumerism, confers an identity and a meaning. Since for Oedipa people who engage in a "calculated withdrawal, from the life of the Republic, from its machinery [the two are here conveniently conflated]" cannot withdraw "into a vacuum (could they?), there had to exist the separate, silent, unsuspected world" (124-25).

The chance these various withdrawers are as different from one another as they all are from mainstream, upscale consumers like herself never really occurs to Oedipa; the thought they might evolve according to their own interactions and the pressure of events rather than a timetable of public destiny is also far from her mind. Furthermore, the way Oedipa has constructed the two realms of Official and Alternative America, there is inevitably between the two of them the same sort of 
unrelenting hostility one associates with the superpowers, the only difference being that these two competing historical narratives coexist within one country. There can be between these two narratives, the implication is, no fruitful interaction; the twain may meet, but never to learn from each other, only to kill. The Tristero, not without reason, are always figured as angels of death.

Musing on the conspiracy she thinks she has uncovered, Oedipa asks herself, "how had it ever happened here, with the chances once so good for diversity?" (181). This is among the most ironical lines in the novel, for in her "dark night" of wandering Oedipa in fact encountered great diversity--more, arguably, than she could deal with at the time. Perhaps the sacred narrative with its revelation safely postponed until death was a way of shielding the witness from the more direct impact of what she saw.

Whether or not such psychologizing befits a character like Oedipa, these competing narratives, as they evolve, do have the effect of further buffering, insulating her from the world she encounters. In fact, what the grand schemes do, both to her and probably to most readers, is to cause them to overlook the very tragic realities they have the potential to confront in Oedipa's midnight journey: "she might have found The Tristero anywhere in her Republic . . . if only she'd looked. ... If only she'd looked" (179). Between the first lament on the part of Oedipa ("if only she'd looked") and its repetition, perhaps by Oedipa, perhaps by another narrative voice, falls the shadow of a certain irony. She wishes she had picked up her clues to Tristero earlier; but there is also the possibility that even in pursuing the clues she has not really looked.

What Oedipa does not understand, Hite argues, is that what she thinks of as waste--and what may in fact be waste--does not need some larger narrative in which to have meaning conferred upon it: "The pathos and even tragedy that redeem Oedipa's world from banality emerge as a by-product of the quest--as the residue or waste generated by her being-toward transcendence" (Hite 88-89). ${ }^{20}$

There are three major reasons why the waste Oedipa observes as she pursues her project becomes more central than what she is after. First of all, the "waste" of subcultures Oedipa encounters in San Francisco actually has its own forms of significance, which are mutually created and sustained by community, not reducible to features of the administered culture with which Oedipa is chiefly familiar. Only when meaning is thought of as a noun rather than a gerund does this process seem insignificant. It is in this sense that the underground postal system provides a clue to the existences of these subcultures. It is, after all, the only putatively two-way communications medium 
that figures prominently in this novel; and something like that two-way communication is intrinsic to the formation of values and meanings within any culture, no matter whether they can be fully assimilated to the larger, dominant culture or not.

Second, as we have seen, the values and meanings generated by these marginal cultures are in fact not, strictly speaking, opposed to those of the administered culture. Rather, it is precisely the genius of the administered culture and its Maxwell's demons to take what can be used from those cultures and plug them into the system of circulation of goods, a system whose avatar in the novel is Oedipa's dead lover. It is in this sense that the Gl's in Fangoso Lagoon are the proper occasion for Oedipa's journey: they are the dead--that community of outcasts--who have been used three times, as sacrifice in war, as commodities and as advertisement. Having first "used up" the servicemen in war, the system resulting from the war can then use their remains twice more. What is scandalous is not that the dead Gl's are waste--this is precisely why they would be honored--but that they are used by the postwar system of Pierce Inverarity. Through this central mystery, whose solution is not some Tristero conspiracy but the mere banal workings of contemporary capitalism, the novel dramatizes the complicity between the "American way of life," whose child Oedipa Maas is, and various outcast groups, the dead being the most extreme example. The relation of the dominant culture and its machinery to its marginal or outcast others, then, is one not of contestation but of colonization.

Finally, and most importantly, the fact of waste itself becomes crucial. Its resonance is strongest of all in the scene where Oedipa comforts a dying sailor. Mendelson has alerted us to the sacred as a theme in Lot 49; but what is less immediately obvious is the nature of that sacred. It is not a sacred of the sort established by some teleology or founding national myth, whether of "America" or "Tristero." Rather, the sacred is confronted in "a time differential, a vanishingly small instant in which change had to be confronted at last for what it was, where it could no longer disguise itself as something innocuous like an average rate" (129). The moment of this sailor's death is indeed sacred, but in the sense in which Georges Bataille defines it: a privileged instant. ${ }^{21}$ This privileged instant is also an instant of loss, of waste.

It is simultaneously an instant of metaphor, of the transfer of meaning. As David Cowart points out, "Metaphor, the word itself, also has a suggestive etymology; it comes from Greek pherein (to bear) and meta (across, beyond), and indeed it bears us into the beyond along with Oedipa's old sailor." ${ }^{22}$ The real transfer of meaning here is 
founded, ironically, upon the loss of substance, upon death. Envisioning the sailor's mattress burning "in his Viking's funeral," Oedipa feels "as if she had just discovered the irreversible process" (128), and does "not know where she [is]" (129). These moments of loss and bewilderment constitute the closest thing to genuine revelation in the entire novel, because it is only here that change is at least obliquely confronted for what it is. That Oedipa holds the old sailor in a fashion reminiscent of the Pieta has been observed before; and there is a clear thematic link to the incident at Lago di Pietà. But above all, there is the fact of death, of loss, in all its irreversibility: not as part of a mystery story to be solved on the final page, or of some grand narrative of national destiny--or for that matter of anarchist destiny, as Jesús Arrabal hopes for. It is only in feeling that keen edge of suffering and loss that Oedipa at all enters into the interactive process by which meaning really is created. Metaphor, the carryingacross of meaning, is here part of the same process that carries Oedipa across the Styx with her boatman. For a moment at least, rather than seeing metaphor as a simple matter of either/or, Oedipa sees "[t]he act of metaphor" as "a thrust at truth and a lie, depending where you were: inside, safe, or outside, lost" (129; emphasis added). It occurs in a between-space where meaning is communicated and distorted at the same time, always at once inside and outside. Unlike the meaning proffered by revelation, this meaning is hers not because Oedipa has died but because she has almost died, has witnessed death and been altered by it herself.

The transfer of meaning has taken place, not because of being inside or outside, but because of a proximity, one registered by touch:

She was overcome all at once by a need to touch him, as if she could not believe in him, or would not remember him, without it. Exhausted, hardly knowing what she was doing, she came the last three steps and sat, took the man in her arms, actually held him, gazing out of her smudged eyes down the stairs, back into the morning. (126)

This passage registers the vocabulary of the sacred. We might say Oedipa needs to "believe in" this sailor just as Mucho needs to "believe in" his rock groups, but the facetious tone with which other such aspirations are mentioned is lacking here; and this tonal shift, characteristic of the entire passage concerning the sailor, coincides with one of the few instances when the heroine touches another person, leaves the insulation of her tower. What would otherwise be a potential source of satire on the topic of the heroine's need for belief is in fact, then, more of a counterpoint to the forms of sacredness in the text that derive from some obsessional teleological system. What is communicated by this scene is not assimilable into any sign system, 
including, of course, that of the narrative itself; however, one might say that such moments as these are in fact central to what Baudrillard would call the symbolic exchange. The sailor's giving Oedipa a letter to deliver, unknowingly, to a trash bin is evocative of the dead letter office in Melville's "Bartleby the Scrivener," and his mattress constitutes a "memory bank to a computer of the lost" (126). Perhaps Oedipa's desire to remember the sailor in her turn, like her sense that the dead should persist, is part of her own ambition to become that computer as well. But the "data" she receives is hardly retrievable by computer. Indeed, irretrievability, disinheritance, waste are the essence of what is communicated. The fact that a man is dying and that nothing can be done about it--the fact that, as Oedipa says, "I can't help' " $(126)$, even though she wishes to--that is above all what is conveyed, the meaning that is transferred.

The meaning of this sailor's fate, and by extension the fate of those other Gl's, is the pathos of the fate itself. This, and not some solution to the mystery or clue to national destiny, is what Oedipa must learn. Such a meaning would be hard to assimilate to her administered world not only because it concerns an element that world prefers to ignore but also because the sorry lack of meaning--the senselessness-of the fate is its primary sense. What is communicated by such meaning as this, then, is the loss of reassuring, fixed and rational meaning itself: a loss against which the administered world in both its secular and its quasi-religious forms struggles (not without reason).

It is small wonder that, given Oedipa's immersion in that world's reassuring sign-system, she recovers abruptly from this traumatic moment and resumes happily her detective ways. Emblematically, instead of reading the manifest message--"WASTE"--on the container where she deposits the sailor's letter, she decides (no doubt with relief) to interpret this message as some other message--"She had to look closely to see the periods between the letters" (130)--with its own teleology, albeit one the reverse of the official destiny: "We Await Silent Tristero's Empire" (169). This turn to teleology (or counterteleology) is an index of what the entire novel works to depict, both in Oedipa's trajectory and in that of the reader whose chief access to the narrative is through Oedipa; in recuperating the loss of this sailor by situating his fate within a narrative of destiny, she is not (as some critics have seemed to believe) approaching the sacred but in fact fleeing from it. After the brief, flaming exception to the detective-story rule of this novel, both Oedipa and the reader flee to the hope of full meaning as promised by both sacred and secular narratives, ignoring the possibility that it is the loss of meaning, the waste of a life, that itself constitutes those "words she never wanted to hear" (54). At the 
same time, this moment of loss is, properly speaking, sacred, because one of the most resonant moments in the book.

Oedipa is wise enough to intuit regions of experience that are unassimilable to the administered world of her background. But in positing all that does not fit into this world as a "mystery" in need of solving by its own narrative, she only duplicates the meaning processes at work in the dominant culture, then inverts them. The truest gauge of the mystery at work among the disinherited was available to her in her encounter with the sailor, if only she'd noticed. That the opportunity is almost incidental to the design of Oedipa's quest and that the meaning is (despite Oedipa's desire) so easily forgotten attest to the miracle, the inverse rarity, of such moments, and attest as well to the valiant and altogether sensible efforts of cultures, heroines and readers to forestall such moments and, if they should occur, to forget that they ever did. Such willful amnesia in the face of absolute loss may characterize all cultures, including those marginal cultures sketched by Pynchon. However, their very lack of material resources forces those within the marginal cultures more often to confront realities such as the one Oedipa briefly encounters here.

The incident pierces the narrative just as it pierces the tower of Oedipa's solitude, but briefly. Soon, mercifully, the barriers are erected again; the narrative that provides the tower's tapestry resumes its course. The reader, after this interlude, follows the unfolding story, comforted by the promise of full meaning. No doubt by the time that meaning is withheld, the reader is scarcely aware that the dilemmas presented by Oedipa, lost amidst her binary ones and zeroes, are after all quite gentle compared to the glimpse of the abyss that she and the reader have fled many pages ago.

-The Ohio State University

Notes

1 "The Crying of Lot 49," Thomas Pynchon, Ed. Harold Bloom (New York: Chelsea, 1986) 175-89. While with a detective story "you start with a mystery and move towards a final clarification ... in Pynchon's novel we move from a state of degree-zero mystery . . . to a condition of increasing mystery and dubiety" (175). Tanner is shrewd to note the crucial distinction between Pynchon's novel and a detective story: we shall see, moreover, that, paradoxically, it is the kind of clarification sought by the particular detective that Oedipa is that results in this "increasing mystery and dubiety."

2 "The problem is finally about America. There is the America of San Narciso, but is there perhaps another America?" (Tanner 188).

${ }^{3}$ In addition to Tanner, Edward Mendelson isolates this feature of the story, in "The Sacred, the Profane, and The Crying of Lot 49," Pynchon: A Collection of Critical 
Essays, ed. Edward Mendelson (Englewood Cliffs, NJ: Prentice-Hall, 1978) 112-46. "Where the object of a detective story is to reduce a complex and disordered situation to simplicity and clarity, and in doing so to isolate in a named locus the disruptive element in the story's world, The Crying of Lot 49 starts with a relatively simple situation, and then lets it get out of the heroine's control" (123).

${ }^{4}$ Theodor Adorno, for instance, uses this phrase in Negative Dialectics, trans. E. B. Ashton (New York: Seabury, 1973).

${ }^{5}$ Thomas Pynchon, The Crying of Lot 49 (1966; New York: Perennial, 1986) 33.

${ }^{8}$ For a Critique of the Political Economy of the Sign, trans. Charles Levin (St. Louis: Telos, 1981) 32, 65-66.

"Baudrillard himself discusses fashion, whose "compulsion to innovate signs" and "perpetual production of meaning--a kind of meaning drive--and the logical mystery of its cycle" are all part of "logical processes [that] might be extrapolated to the dimension of 'culture' in general--to all social production of signs, values and relations" (78-79).

${ }^{8}$ Thomas H. Schaub's fine article "A Gentle Chill, An Ambiguity': The Crying of Lot 49" (Critical Essays on Thomas Pynchon, ed. Richard Pearce (Boston: G. K. Hall, 1981] 51-68, esp. 54-55) takes as part of its ambit the explicit forming of bonds between Pynchon's text and Marshall McLuhan's Understanding Media. Certainly such relays are hard not to make regarding a novel that compares a postwar housing tract to a radio's circuit card.

${ }^{9}$ This point contradicts the drift of Adorno and Horkheimer's argument in Dialectic of Enlightenment, trans. John Cumming (New York: Continuum, 1986), esp. "The Culture Industry: Enlightenment as Mass Deception," 120-67. Whereas they tend to emphasize the "stereotyped appropriation of everything, even the inchoate, for the purposes of mechanical reproduction" (127), the administered world of Pynchon's text draws its sustenance from subcultures and marginal groups, while despising them at the same time.

${ }^{10}$ Baudrillard has described this process of use and displacement as the movement from the socially direct, interactive world of symbolic exchange to a system of signobjects with the social meanings affixed to them in various ways. Baudrillard, ever the anthropologist, links this process to that of fetishization, which he posits as in itself a constant and not necessarily pernicious one: "As a power that is transferred to beings, objects and agencies, it [fetishism] is universal and diffuse, but it crystallizes at strategic points so that its flux can be regulated and diverted by certain groups or individuals for their own benefit" (89). What William Blake accused the ancient priests of doing, monopolizing the deities, is roughly what Baudrillard charges consumer society in this century with doing. He points out that "fetish" originally tended to mean fabrication or artifact. Hence, a fetish was the product of artisanal labor and in some measure the result of a conscious "cultural sign labor." In consumer society, ironically, objects become even more fetishistic than those older fetish objects, at least insofar as they are "given and received everywhere as force dispensers (happiness, health, security, prestige, etc.). The labor of fabrication which was part of the ancient fascination with the fetish is now suppressed, and what replaces it for inspection is some sort of magical force imputed to the object itself" (91). Baudrillard's argument effects an elegant reversal whereby the modern-day consumer is prey to a fetishism of the object--the 
tendency to impute properly internal power to external things--more extreme than earlier forms because more isolated from the social process of meaning-making. (One thinks of Oedipa's magically flying aerosol can.)

"Ideas of Order in the Novels of Thomas Pynchon (Columbus: Ohio State UP, 1983) 90 .

12 "All of Pynchon's characters are readers, but Oedipa in The Crying of Lot 49 is the protagonist who is presented most consistently as a reader" (Maureen Quilligan, "Thomas Pynchon and the Language of Allegory," Pearce 200).

13 "By becoming the executor of Pierce Inverarity's last will and testament, Oedipa comes close to a kind of sacred discipleship" (Quilligan 188).

${ }^{14}$ Marie-Claude Profit makes much of the way metaphor, like death itself, connects two worlds customarily divergent. Citing John Nefastis's statement that entropy constitutes a metaphor because it connects the worlds of information flow and energy. Profit emphasizes "An important word in Nefastis' remarks: 'it connects'" ("The Rhetoric of Death in The Crying of Lot 49," trans. Margaret S. Langford, Pynchon Notes 10 [1982]: 31).

${ }^{15}$ Mendelson also makes this relay: "The logical response to a world where one creates, alone, the only order--where one ignores the data of the word-is nihilistic despair. And the logical culmination of an exclusive devotion to the spirit is the sloughing-off of the flesh" (125).

${ }^{16}$ Hite puts it this way: As Oedipa "sees it, if her 'project,' the Tristero, does not exist, the codes break down. . . Either the 'residue' of Oedipa's experience means that the Tristero exists, or it does not mean" (77).

17 On this point cf. Hite: Oedipa "sees the world behind the tapestry and finds that it is not a void. But she does not understand what she sees because she is looking only for evidence of the Tristero. . . . The Tristero has forced her to see, but she believes she sees only clues to the Tristero" (86-87).

${ }^{18}$ Hite remarks that Oedipa's desire for "a definitive message" is what "pushes the narrative forward toward a conclusion so loaded with portents that the attentive reader may recognize that it is unrealizable" (88). With this I concur, although her preceding comment is perhaps the only part of this superb treatment I cannot agree with: "The post horn is a mark of kinship. It calls attention to the 'wasted' elements of American society and suggests that they compose an alternative society, communicating by different means and relaying different messages" $(88)$. To the extent that Hite goes along with what the post horn "suggests" and reads the clues gathered by Oedipa as indicating this "alternative society," I think this forecloses the other and likelier possibility that the apparatus of linkage itself is chiefly something Oedipa brings to her encounters. In other words, the Tristero, even if it is in fact a parallel organization for " $X$ number of Americans" who are alienated from official culture (which is far from demonstrated), may not necessarily be the organization for all the marginal, "'wasted' elements." The mere fact that all the drifters and subcultures Pynchon presents are alienated from mainstream America does by no means show that they are all perforce in league with one another. 
${ }^{19}$ Louis Mackey discusses this exploration of Pynchon's with special emphasis on Gravity's Rainbow rather than The Crying of Lot 49, but he accounts for the sort of Manicheanism that produces Oedipa's dilemma of narrative and counternarrative ("Thomas Pynchon and the American Dream," Pynchon Notes 14 [1984]: 7-22).

${ }^{20}$ Hite mentions elsewhere in this connection that the "world of shared meanings" encountered by Oedipa "lacks the coherence of a myth that moves toward a projected fulfillment, but it is not incoherent" (81). I take this to mean that socially produced meanings emerge from interactive processes that are not necessarily subject to prior ratification by some official sacred narrative, nor even by official consumer society.

21 "The term privileged instant is the only one that, with a certain amount of accuracy, accounts for what can be encountered at random in the search Ifor the sacred]; the opposite of a substance that withstands the test of time, it is something that flees as soon as it is seen and cannot be grasped" ("The Sacred," Visions of Excess: Selected Writings, 1927-1939, trans. Allan Stoekl [Minneapolis: $U$ of Minnesota P, 1985] 241; emphasis in original).

22 Thomas Pynchon: The Art of Allusion (Carbondale: Southern Illinois UP, 1980) 108. 